\title{
High amplitude contractions in the middle third of the oesophagus: a manometric marker of chronic alcoholism?
}

L Grande, R Monforte, E Ros, V Toledo-Pimentel, R Estruch, G Lacima, A Urbano-Marquez, C Pera
Previous studies have shown oesophageal motor abnormalities after short-term administration of ethanol, both in alcoholic patients ${ }^{1}$ and in healthy volunteers, ${ }^{23}$ but there are few reports on the longterm effects of ethanol on oesophageal motor function. ${ }^{14-7}$ Moreover, although oesophageal motility changes have been postulated to be both an important factor in the pathogenesis of oesophagitis and contributory to the increased incidence of oesophageal carcinoma in chronic alcoholic patients, ${ }^{89}$ systematic evaluation of oesophageal mucosal disease by endoscopy has rarely been performed, ${ }^{6}$ whereas there are no reports of alcoholic patients assessed for reflux with prolonged intraoesophageal $\mathrm{pH}$ monitoring.

The aims of this study were to evaluate oesophageal motor function with manometry and 24 hour $\mathrm{pH}$ monitoring in an unselected group of alcoholic patients and to compare their oesophageal motility patterns with those of healthy controls and of patients with well defined oesophageal diseases. In addition the frequency of oesophageal mucosal abnormalities was endoscopically assessed in alcoholic patients. Finally, oesophageal motility was reassessed after six months of purported abstinence from alcohol. controls) in $13(57 \%)$, the ratio lower/ middle amplitude was $<0.9$ in $15(65 \%)$ $(>0.9$ in all control groups), and the lower oesophageal sphincter was hypertensive (>23.4 mm Hg, $\mathrm{P95}$ of healthy controls) in $13(57 \%)$. All three abnormalities were present in five $(22 \%)$. Abnormal reflux (per cent reflux time $>2 \cdot 9$, P95 of healthy controls) was shown in $12(52 \%)$ alcoholic patients, and was unrelated to peristaltic dysfunction. Subclinical neuropathy in 10 patients did not effect oesophageal abnormalities. Oesophageal motility abnormalities persisted at six months in six patients with ongoing alcoholism, whereas they reverted towards normal in 13 who remained abstinent; reflux, however, was unaffected.

Conclusions-Oesophageal peristaltic dysfunction and reflux are frequent in alcoholism. High amplitude contractions in the middle third of the oesophagus seem to be a marker of excessive alcohol consumption, and tend to improve with abstinence.

(Gut 1996; 38: 655-662)

Keywords: alcohol, oesophagus, oesophageal motility, 24 hour intraoesophageal $\mathrm{pH}$ monitoring, gastro-oesophageal reflux, oesophagitis.

\section{Methods}

\section{PATIENTS}

The Alcohol Unit of the Hospital Clinic of Barcelona treats patients who seek assistance in stopping their addiction to alcohol and who have no signs or symptoms of other diseases. Alcohol dependence was diagnosed in all these patients according to DSM III R. ${ }^{10}$ In October 1991 a clinical study of the effects of alcoholism on neuromuscular function ${ }^{11}$ that required hospital admission was started. Because of limited bed availability, only the first patient to register on Monday of each week was asked to participate. Prerequisites for entering the study were: daily ethanol consumption greater than $100 \mathrm{~g}$ in the previous two years, and absence of substance abuse. All had smoked one to two packs of cigarettes a day since the second decade of their lives and usually drank one to two cups of coffee per day. During the first week after admission patients underwent tests to rule out both ongoing alcohol consumption and withdrawal syndrome; in addition, a complete biochemical profile and specific tests for alcohol related 
neuromuscular damage were performed. Twenty three consecutive patients without evidence of either alcohol ingestion or withdrawal syndrome during admission, no prior history of gastroduodenal ulcer or oesophagogastric surgery, and no overt haematological, biochemical or neuromuscular alterations were selected for oesophageal studies, which were performed 7-10 days after admission (baseline evaluation) and again after six months of alcohol abstinence (late evaluation).

Drugs active on oesophagogastric motility or secretion were forbidden for seven days before oesophageal studies. Antacids were permitted for symptom relief except on the day of oesophageal motility testing.

\section{CONTROL GROUPS}

Three control groups, matched for sex and age to the chronic alcoholic patients, were selected from our Digestive Motility Unit files for comparison of oesophageal motility patterns and 24 hour pHmetry data. The data bank contains tracings filed according to diagnosis and not to manometric findings.

\section{Healthy controls}

The tracings of 23 volunteers ( 20 men; three women, mean age 39 , range 22-57) were analysed. None of them had oesophageal symptoms, used antacid preparations or drugs active on oesophagogastric motility or secretion, and an acid perfusion test (Bernstein) was negative in all subjects.

\section{Nutcracker oesophagus}

The recordings of 23 patients ( 20 men; three women, mean age 50, range 36-61) with a diagnosis of nutcracker oesophagus were selected. All the patients were studied because of non-cardiac chest pain or dysphagia in the absence of heartburn or regurgitations, and all had a normal endoscopic appearance of the oesophageal mucosa. The nutcracker oesophagus was diagnosed on the basis of high amplitude peristaltic waves $(>150 \mathrm{~mm} \mathrm{Hg}$ 95th confidence limit of our laboratory) in the lower two thirds of the oesophageal body.

\section{Gastro-oesophageal reflux disease}

The tracings of 23 patients $(20$ men; three women, mean age 43, range 21-62) with gastro-oesophageal disease were included. All patients were diagnosed when compatible symptoms were associated with a positive 24 hour intraoesophageal $\mathrm{pH}$ monitoring, in the absence of gastroduodenal ulcer, previous upper gastrointestinal surgery, or longterm NSAID ingestion. Heartburn was present in 22 patients $(96 \%)$, regurgitations in $19(83 \%)$, and dysphagia in nine (39\%). Sixteen patients had erosive oesophagitis by fibreoptic endoscopy.

The study was approved by the ethics committee of the Hospital Clinic i Provincial of Barcelona on August 1991, and written informed consent was obtained from all subjects included in the study.

\section{CLINICAL AND LABORATORY EXAMINATIONS}

The amount and type of alcoholic beverages consumed, the pattern of drinking, and the duration of alcohol abuse were recorded. Using a structured questionnaire, one physician (RM) obtained a detailed history of oesophageal symptoms, ethanol intake and dietary habits. Gastro-oesophageal reflux symptoms (heartburn, dysphagia, and regurgitation) were rated on a scale from 0 (none) to 4 (very severe) (maximum score 12). Withdrawal symptoms were evaluated every six hours during the admission period according to the Clinical Institute for Withdrawal Assessment (CIWA) scale (12). A score $>10$ was considered as indicating the presence of withdrawal syndrome. Urinary ethanol concentrations were determined daily during the admission period and every two weeks after hospital discharge during the ensuing six months.

Autonomic and peripheral nervous system function was evaluated as previously described. ${ }^{12}$ Parasympathetic neuropathy was considered if two of the following tests were abnormal: heart rate variations after deep breathing, Valsalva manoeuvre, or standing, whereas sympathetic neuropathy was defined an abnormal variation in blood pressure after either isometric exercise or standing. Peripheral neuropathy was considered as present if the patient had two or more of the following abnormalities: weakness or paresthesia in the lower limbs, absent muscle tendon reflexes, or sensory deficit on physical examination, or all three. Moreover, the peripheral nervous system was assessed by conventional electrophysiological tests.

\section{ENDOSCOPY}

Endoscopy was carried out with an Olympus GIF-Q (Olympus, New Hyde Park, NY) apparatus. The endoscopic appearance of oesophagitis was graded as follows ${ }^{13}$ : grade 0 , normal mucosa; grade I, erythema; grade II, non-confluent erosions: grade III, confluent erosions or circumferential shallow ulcerations, or both; and grade IV, deep ulcer or stricture, or both. Endoscopic pinch biopsy specimens were taken in the distal $5 \mathrm{~cm}$ of the oesophageal body. Histological studies of these specimens were performed without knowledge of the clinical and manometric data.

\section{OESOPHAGEAL MANOMETRY}

Oesophageal motility studies were performed in all subjects as previously described. ${ }^{13} 14$ The system used consisted of three fused polyvinyl catheters (ID $1.1 \mathrm{~mm}$ ). Each catheter had one lateral opening equal in diameter to its circumference and was closed distal to this opening. The recording catheter was arranged to measure intraluminal pressures at three points $5 \mathrm{~cm}$ apart and oriented circumferentially to lie at $120^{\circ}$ to each other. The catheter assembly 
was perfused by a pneumohydraulic capillary system (Arndorfer Medical Specialties, Milwaukee, Wisconsin) at a flow rate of 0.6 $\mathrm{ml} / \mathrm{min} /$ lumen. Each catheter was connected to an external transducer, and the recordings were traced on a multichannel polygraph (Beckman Instruments, Schiller Park, Illinois). Deglutitions were registered using a belt around the neck.

All studies were performed after an overnight fast with the subject in the supine position. The catheter assembly was introduced transnasally without prior sedation or anaesthesia, and positioned with all orifices in the stomach. Intragastric end expiratory pressure was used as zero reference. Recording of the lower oesophageal sphincter pressure was performed by three continuous pull throughs at a rate of $1.5 \mathrm{~cm} / \mathrm{min}$ until the three orifices had transversed the sphincteric zone and entered the oesophagus. The subjects were instructed not to swallow during this part of the test. Then the assembly was immobilised with the distal oesophageal recording site $5 \mathrm{~cm}$ above the upper point of the lower oesophageal sphincter, and oesophageal peristalsis was assessed with 10 wet swallows $(5 \mathrm{ml}$ room temperature water) done at least $30 \mathrm{sec}-$ onds apart. Thus oesophageal pressures were recorded at 5, 10, and $15 \mathrm{~cm}$ above the lower oesophageal sphincter. Although these locations cannot strictly be equated with the three thirds of the oesophagus, for the purposes of this study they will be named lower, middle, and upper third, respectively. Finally, the upper oesophageal sphincter pressure was recorded in the same manner as the lower oesophageal sphincter pressure during a continuous pull through from the oesophagus to the pharynx.

\section{HOUR INTRAOESOPHAGEAL PHMETRY}

Ambulatory 24 hour oesophageal pH monitoring was performed as previously described. ${ }^{15}$ Briefly, after manometric location of the lower oesophageal sphincter, an antimony $\mathrm{pH}$ electrode (Monocrystant mod 91-0011, Synectics Medical, Portugal) was introduced nasally and located $5 \mathrm{~cm}$ above the lower oesophageal sphincter. A reference electrode was attached to the chest. Both electrodes were connected to a portable $\mathrm{pH}$ meter (Digitrapper 6000, Synectics AB, Stockholm, Sweden). The pH meter was calibrated with $\mathrm{pH} 1$ and $\mathrm{pH} 7$ buffers before starting the procedure. Intraoesophageal $\mathrm{pH}$ was monitored during 24 hours, including 15 hours in the erect or sitting position and nine hours supine. All patients were given meals of identical energy value and composition, which were deprived of all substances with a pH lower than 5.0 or higher than $7 \cdot 0$. During the procedure, all the participants were forbidden to smoke, drink coffee, or take drugs active on oesophagogastric motility or secretion. Antacids were not permitted during $\mathrm{pH}$ monitoring. All $\mathrm{pH}$ recordings were analysed by computer using the Esophagogram software program (Synectics AB, Stockholm, Sweden).

\section{DATA ANALYSIS}

\section{Manometry}

Lower oesophageal sphincter pressure was determined from end expiratory gastric pressure to end expiratory sphincteric pressure. Resting lower oesophageal sphincter pressure values were expressed as the mean of nine profiles obtained by three pull throughs. The amplitude, duration, and velocity of progression of 10 consecutive deglutitions were measured 5,10 , and $15 \mathrm{~cm}$ above the upper limit of the lower oesophageal sphincter. Values from each subject were expressed as the mean of 10 recordings obtained at each site. Amplitude was measured from the mean oesophageal baseline to the peak of the contraction and expressed in $\mathrm{mm} \mathrm{Hg}$. The interval from the intersection of lines for mean resting intraoesophageal pressure and the upstroke of the complex to its return to mean resting pressure was recorded as the wave duration and expressed in seconds. The propagation velocity was calculated by measuring the distance between wave peaks taking into account the speed of the registering paper and the distance between recording ports. Simultaneous contractions (tertiary waves) were also recorded. Upper oesophageal sphincter pressure was determined from mean oesophageal baseline to the peak of the contraction and expressed in $\mathrm{mm}$ $\mathrm{Hg}$. Resting upper oesophageal sphincter pressure values were expressed as the mean of three profiles obtained by one pull through.

\section{pHmetry}

A reflux episode was considered to occur whenever the intraoesophageal $\mathrm{pH}$ decreased to less than 4.0 during at least 10 seconds. The following reflux events were analysed: number of reflux episodes, per cent of time $\mathrm{pH}$ was below $4 \cdot 0$ (total, upright, supine), number of episodes longer than five minutes' duration of the longest reflux episode, oesophageal clearance, and overall score. These calculations were made according to the technique described by DeMeester. ${ }^{16}$

\section{STATISTICAL ANALYSIS}

Because manometric and pHmetric data were found to be skewed (Kolmogorov, ShapiroWilks, and Levene tests), all quantitative data are expressed as median and limit values, and non-parametric tests (Wilcoxon or MannWhitney) were used to detect any differences between them. Spearman's correlation coefficients were calculated to detect relations between continuous variables. $p$ Values of $<0.05$ were required for significance.

\section{Results}

CLINICAL AND LABORATORY DATA

The 23 alcoholic patients studied consisted of 20 men and three women and had an age (mean (SD) of 43 (12) (range, 23 to 54). Their reported daily intake of ethanol ranged from 120 to $350 \mathrm{~g}$ (mean, 266 (70) $\mathrm{g}$ over a period of $24.3(8.9)$ years. The total life time of 
TABLE I Manometric and pHmetric findings in the four study groups

\begin{tabular}{|c|c|c|c|c|}
\hline & $\begin{array}{l}\text { Alcohol } \\
(n=23)\end{array}$ & $\begin{array}{l}\text { Controls } \\
(n=23)\end{array}$ & $\begin{array}{l}\text { Nutcracker } \\
(n=23)\end{array}$ & $\begin{array}{l}\text { Gastro-oesophageal reflux } \\
\text { disease }(n=23)\end{array}$ \\
\hline \multicolumn{5}{|l|}{ Oesophageal motility } \\
\hline \multicolumn{5}{|l|}{ Upper oesophageal sphincter } \\
\hline \multicolumn{5}{|c|}{ Peristaltic wave amplitude $(\mathrm{mm} \mathrm{Hg})$} \\
\hline Upper third & $77 \cdot 4(27 \cdot 0-201 \cdot 6)$ & $63 \cdot 1(22 \cdot 1-123 \cdot 6)$ & $85 \cdot 4(51 \cdot 6-174 \cdot 7)$ & $57 \cdot 3(33 \cdot 3-111 \cdot 6)^{\star}$ \\
\hline Middle third & $159 \cdot 3(43 \cdot 5-240 \cdot 3)$ & $84 \cdot 6(39 \cdot 9-129 \cdot 6)^{\star}$ & $213 \cdot 1(160 \cdot 4-361 \cdot 8)^{\star}$ & $73.4(50 \cdot 4-127 \cdot 8)^{\star}$ \\
\hline Lower third & $106 \cdot 2(43 \cdot 7-217 \cdot 8)$ & $100 \cdot 5(47 \cdot 7-157 \cdot 3)$ & $257 \cdot 3(187 \cdot 5-370 \cdot 8)^{\star}$ & $77 \cdot 4(46 \cdot 8-199 \cdot 8)^{\star}$ \\
\hline \multicolumn{5}{|l|}{ Peristaltic wave duration (s) } \\
\hline Upper third & $3 \cdot 5(2 \cdot 4-4 \cdot 4)$ & $3 \cdot 2(1 \cdot 1-4 \cdot 7)$ & $3 \cdot 3(1 \cdot 1-5 \cdot 2)$ & $3 \cdot 5(2 \cdot 3-3 \cdot 9)$ \\
\hline Middle third & $3 \cdot 8(3 \cdot 3-4 \cdot 8)$ & $4 \cdot 8(2 \cdot 7-5 \cdot 6)$ & $4 \cdot 2(2 \cdot 5-6 \cdot 3)$ & $4 \cdot 0(2 \cdot 6-4 \cdot 7)$ \\
\hline Lower third & $4 \cdot 5(3 \cdot 3-6 \cdot 0)$ & $4 \cdot 8(3 \cdot 2-7 \cdot 0)$ & $5 \cdot 0(3 \cdot 2-7 \cdot 4)$ & $4 \cdot 7(3 \cdot 0-6 \cdot 1)$ \\
\hline \multicolumn{5}{|c|}{ Peristaltic wave progression speed $(\mathrm{cm} / \mathrm{s})$} \\
\hline Upper-middle & $3 \cdot 6(1 \cdot 6-6 \cdot 6)$ & $3 \cdot 6(1 \cdot 5-6 \cdot 9)$ & $3 \cdot 0(2 \cdot 0-4 \cdot 5)^{\star}$ & $3 \cdot 7(2 \cdot 0-4 \cdot 5)$ \\
\hline Middle-lower & $3.9(1.9-8.0)$ & $4 \cdot 2(1 \cdot 5-8 \cdot 9)$ & $3 \cdot 1(2 \cdot 4-7 \cdot 8)^{\star}$ & $4 \cdot 4(2 \cdot 9-8 \cdot 0)$ \\
\hline Non-peristaltic waves (\%) & $0(0-100)$ & $0(0-6 \cdot 6)^{\star}$ & $0(0-6 \cdot 6)^{\star}$ & $0(0-20)$ \\
\hline \multicolumn{4}{|l|}{ Lower oesophageal sphincter } & $0.6(0.0-18.5) \star$ \\
\hline Oesophageal pHmetry & $23 \cdot 2(13 \cdot 6-44 \cdot 0)$ & $13 \cdot 2(10 \cdot 1-24 \cdot 5)^{n}$ & $19 \cdot 0(11 \cdot 6-34 \cdot 3)^{x}$ & $9 \cdot 6(2 \cdot 0-18 \cdot 5)^{\star}$ \\
\hline Reflux episodes (n) & $47(1-219)$ & $14(1-43)^{\star}$ & $12(1-32)^{\star}$ & $39(8-174)^{\star}$ \\
\hline Total reflux time $(\%)$ & $2 \cdot 7(0 \cdot 3-28 \cdot 0)$ & $1 \cdot 3(0 \cdot 5-3 \cdot 6)^{\star}$ & $1 \cdot 2(0 \cdot 5-4 \cdot 1)^{\star}$ & $9 \cdot 2(3 \cdot 2-54 \cdot 7)^{\star}$ \\
\hline Upright reflux time (\%) & $3 \cdot 5(0 \cdot 3-41 \cdot 1)$ & $2 \cdot 2(0 \cdot 2-5 \cdot 4)^{\star}$ & $2 \cdot 3(0 \cdot 1-5 \cdot 3)^{\star}$ & $10 \cdot 3(3 \cdot 4-45 \cdot 7)^{\star}$ \\
\hline Supine reflux time $(\%)$ & $1 \cdot 1(0 \cdot 2-27 \cdot 2)$ & $0.2(0.3-4.3)^{\star}$ & $0 \cdot 2(0 \cdot 2-3 \cdot 0)^{\star}$ & $5 \cdot 2(0.2-89 \cdot 5)^{\star}$ \\
\hline Refluxes $>5 \min (n)$ & $1(0-14)$ & $1(0-2)^{\star}$ & $1(0-2)^{\star}$ & $6(0-54)^{\star}$ \\
\hline Longest reflux (min) & $16(0.5-60)$ & $5(0.5-14)^{\star}$ & $6(0 \cdot 5-9)^{\star}$ & $29(4-270)^{\star}$ \\
\hline Oesophageal clearance & $1 \cdot 3(0 \cdot 2-4 \cdot 1)$ & $1 \cdot 0(0 \cdot 1-2 \cdot 4)$ & $0.7(0 \cdot 1-1 \cdot 6)^{\star}$ & $3.3(0.7-11 \cdot 1)^{\star}$ \\
\hline pHmetry score & $13 \cdot 2(6 \cdot 2-75)$ & $6 \cdot 1(5 \cdot 2-11 \cdot 9)^{\star}$ & $5 \cdot 5(3.8-20 \cdot 3)^{\star}$ & $42 \cdot 7(13 \cdot 8-97 \cdot 3)^{\star}$ \\
\hline
\end{tabular}

${ }^{\star} \mathrm{p}<0.05 v$ alcohol.

ethanol intake was $37(20) \mathrm{kg}$ of alcohol per $\mathrm{kg}$ body weight. The pattern of drinking was continuous excessive ethanol intake as part of everyday life. Ethanol was consumed mainly in the form of wine, beer, and brandy and less often as anisette and gin.

On specific questioning, 14 of 23 (61\%) chronic alcoholic patients had oesophageal symptoms. Twelve patients had heartburn (three daily, day time and night, two daily during day time only, and seven occasional episodes, less than seven days a month), and in four of them regurgitation was also present. Five patients reported mild oesophageal dysphagia (two in association with heartburn, and three without other symptoms); four patients had only occasional difficulty swallowing, and a single patient had daily dysphagia. No patients complained of chest pain.

Preclinical alcoholic neuropathy was detected in 10 patients (five with both peripheral and autonomic impairment, four with isolated peripheral neuropathy, and one with autonomic disease alone).

\section{ENDOSCOPY}

Of the 23 patients, 17 had a normal appearance of the oesophageal mucosa, three grade II oesophagitis, and two grade III oesophagitis. A 47 year old man with no digestive symptoms disclosed a $3 \mathrm{~cm}$ polypoid lesion in the upper third of the oesophagus which, on histological examination, was diagnosed as a moderately differentiated squamous cell carcinoma. Five of 17 patients with a normal endoscopic appearance of the oesophageal mucosa had abnormal biopsy specimens disclosing a thickened basal layer, enlarged pegs, and neutrophilic infiltration.

\section{BASELINE STUDIES}

Oesophageal motility

Alcoholic and gastro-oesophageal reflux patients had significantly $(p<0.05)$ higher upper oesophageal sphincter pressures in comparison to those seen in healthy controls or nutcracker oesophagus patients (Table I).

The amplitude of peristalsis in the upper third of the oesophagus was similar in the alcoholic, healthy control, and nutcracker oesophagus groups (Table I). On the other hand, middle third amplitude in alcoholic patients was significantly $(p<0.05)$ higher than that of controls, whereas lower third amplitude was again similar in the alcoholic and control groups. Not unexpectedly, patients with the nutcracker oesophagus had the strongest peristalsis in the lower two thirds of the oesophagus, while those with gastro-oesophageal reflux disease disclosed the weakest peristaltic waves of all the groups. Unexpectedly, alcoholic patients disclosed a median amplitude in the middle third of the oesophagus, which was $50 \%$ higher than median distal amplitude (Table I). A plot of individual data points of the quotient lower/middle amplitude for all the

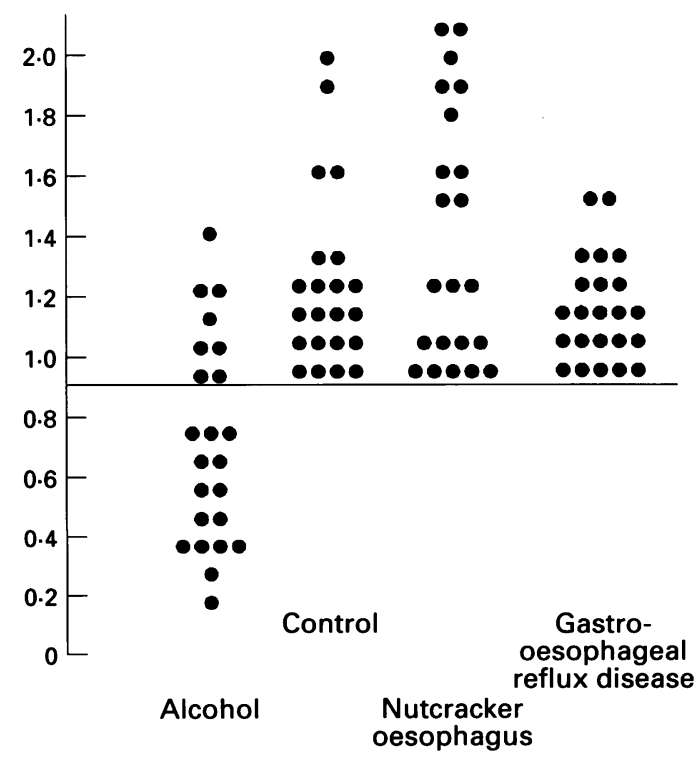

Figure 1: Ratio between lower amplitude and middle amplitude of oesophageal peristalsis (medians) in the four study groups. 
TABLE II Manometric findings in alcoholic patients in relation to the detection of abnormal reflux by 24 hour $\mathrm{pH}$ monitoring

\begin{tabular}{lcc}
\hline & Reflux $(n=12)$ & No reflux $(n=11)$ \\
\hline Upper oesophageal sphincter pressure (mm Hg) & $51 \cdot 2(23 \cdot 8-89 \cdot 1)$ & $53 \cdot 7(30 \cdot 8-103 \cdot 3)$ \\
Peristaltic wave amplitude (mm Hg) & & \\
$\quad$ Upper third & $74 \cdot 8(27 \cdot 0-201 \cdot 6)$ & $82 \cdot 4(28 \cdot 1-183 \cdot 6)$ \\
$\quad$ Middle third & $150 \cdot 1(43 \cdot 5-240 \cdot 3)$ & $162 \cdot 7(49 \cdot 9-229 \cdot 6)$ \\
$\quad$ Lower third & $98 \cdot 0(43 \cdot 7-217 \cdot 8)$ & $120 \cdot 0(47 \cdot 7-207 \cdot 3)$ \\
Peristaltic wave duration (s) & $3 \cdot 5(2 \cdot 6-4 \cdot 4)$ & $3 \cdot 4(2 \cdot 4-4)$ \\
$\quad$ Upper third & $3 \cdot 7(3 \cdot 3-4 \cdot 2)$ & $3 \cdot 8(3 \cdot 4-4 \cdot 8)$ \\
$\quad$ Middle third & $4 \cdot 3(3 \cdot 3-5 \cdot 2)$ & $4 \cdot 8(3 \cdot 7-6)^{\star}$ \\
Lower third & $4(2 \cdot 3-6 \cdot 6)$ & $2 \cdot 4(1 \cdot 6-6 \cdot 6)^{\star}$ \\
Peristaltic wave progression speed (cm/s) & $4 \cdot 5(2 \cdot 9-8)$ & $2 \cdot 6(1 \cdot 9-6)^{\star}$ \\
Upper-middle & $0(0-100)$ & $0(0-67)$ \\
Middle-lower & $22 \cdot 3(13 \cdot 6-44 \cdot 0)$ & $23 \cdot 8(10 \cdot 1-21 \cdot 5)$ \\
Non-peristaltic waves (\%) & $0 \cdot 9(0 \cdot 3-1 \cdot 3)$ & $0 \cdot 7(0 \cdot 2-1 \cdot 3)$ \\
Lower oesophageal sphincter pressure (mm Hg) & \\
Lower/middle amplitude ratio & & \\
\hline
\end{tabular}

${ }^{\star} \mathrm{p}<0.05 v$ reflux. with nutcracker oesophagus had a speedier peristalsis (Table I). A significantly $(\mathrm{p}<0.05)$ higher proportion of non-peristaltic waves was seen in alcoholic patients in comparison to healthy controls and nutcracker oesophagus patients (Table I).

\section{Hour intraoesophageal pHmetry}

The results obtained by ambulatory 24 hour intraoesophageal $\mathrm{pH}$ monitoring are shown in Table I. Most reflux events had higher values in the alcoholic group than in healthy controls or nutcracker oesophagus patients, although they were lower than those seen in gastrooesophageal reflux patients.

Twelve alcoholic patients (52\%) had abnormal reflux by $24 \mathrm{~h}$ pHmetry (per cent reflux time $>95$ th percentile $(2.9)$ of the healthy control group). Table II shows the comparison of relevant manometric data in alcoholic patients with and without reflux. Although refluxers tended to have lower amplitudes than nonrefluxers, none of the differences were statistically significant. The lower/middle amplitude ratio was also similar in alcoholic patients with and without reflux (Table II).

Seven of 12 patients with heartburn, and four of five with dysphagia had abnormal reflux by 24 hour pHmetry. Oesophagitis (microscopic or macroscopic) was associated with reflux in eight of 10 cases. The asymptomatic patient with oesophageal carcinoma also had abnormal reflux by 24 hour $\mathrm{pH}$ monitoring. with a normal increase of amplitude from the middle to the distal oesophagus.

The median resting lower oesophageal sphincter pressure was significantly $(p<0.05)$ higher in the alcoholic patients than in healthy controls, patients with the nutcracker oesophagus or gastro-oesophageal reflux disease patients (Table I). Thirteen of $23(57 \%)$ alcoholic patients had lower oesophageal sphincter pressures above the 95 th percentile $(23.4 \mathrm{~mm}$ $\mathrm{Hg}$ ) of the healthy control group and could thus be defined as showing a hypertensive lower oesophageal sphincter. As expected, as a group, gastro-oesophageal reflux disease patients had a median lower oesophageal sphincter pressure, which was significantly $(p<0.05)$ lower than that of the other three groups.

In the alcoholic group the amplitude of oesophageal peristalsis was unrelated to lower oesophageal sphincter pressure $(r=0.08$ for upper amplitude, $r=0.05$ for middle amplitude, and $r=0.30$ for lower amplitude). Ten of 13 alcoholic patients with hypertensive lower oesophageal sphincter showed a lower/middle amplitude ratio $<0 \cdot 9$. Five patients $(22 \%)$ disclosed the triple oesophageal dysmotility pattern of hypertensive lower oesophageal sphincter, middle amplitude $>150 \mathrm{~mm} \mathrm{Hg}$, and lower/middle amplitude $<0 \cdot 9$.

No significant differences were shown between alcoholic patients and the other three groups of patients regarding duration of peristaltic waves (Table I). The velocity of progression of peristaltic waves was similar in alcoholic, healthy controls, and gastrooesophageal reflux patients, whereas patients
Oesophageal function tests in relation to neuropathy Comparison of clinical, manometric, and pHmetric data in 10 patients with and 13 without preclinical alcoholic neuropathy showed no statistically significant differences. When comparing patients with and without peripheral neuropathy and those with and without autonomic neuropathy, it was also apparent that neuropathy had no influence on oesophageal function.

\section{LATE EVALUATION}

The patient with oesophageal cancer was subing 22 patients were followed up in the alcoholism unit. Periodic determinations of ethanol in urine were performed to assess alcohol ingestion. Nineteen of 22 patients were available for evaluation at six months. Ongoing alcoholism was diagnosed in six patients, whereas 13 patients remained abstinent. Oesophageal motility studies were performed in the six patients with active alcoholism while disclosing a positive alcoholaemia $(1.20(0.62)$ $\mathrm{g} / \mathrm{l}$, range $0 \cdot 64-2 \cdot 86 \mathrm{~g} / \mathrm{l}$ ).

\section{Oesophageal motility}

Figure 2 shows that, as a group, patients who kept drinking continued to disclose high amplitude contractions of the middle oesophagus, whereas this motility disorder was no longer present in those who abstained from alcohol. In mitted to oesophagogastrectomy. The remain- 


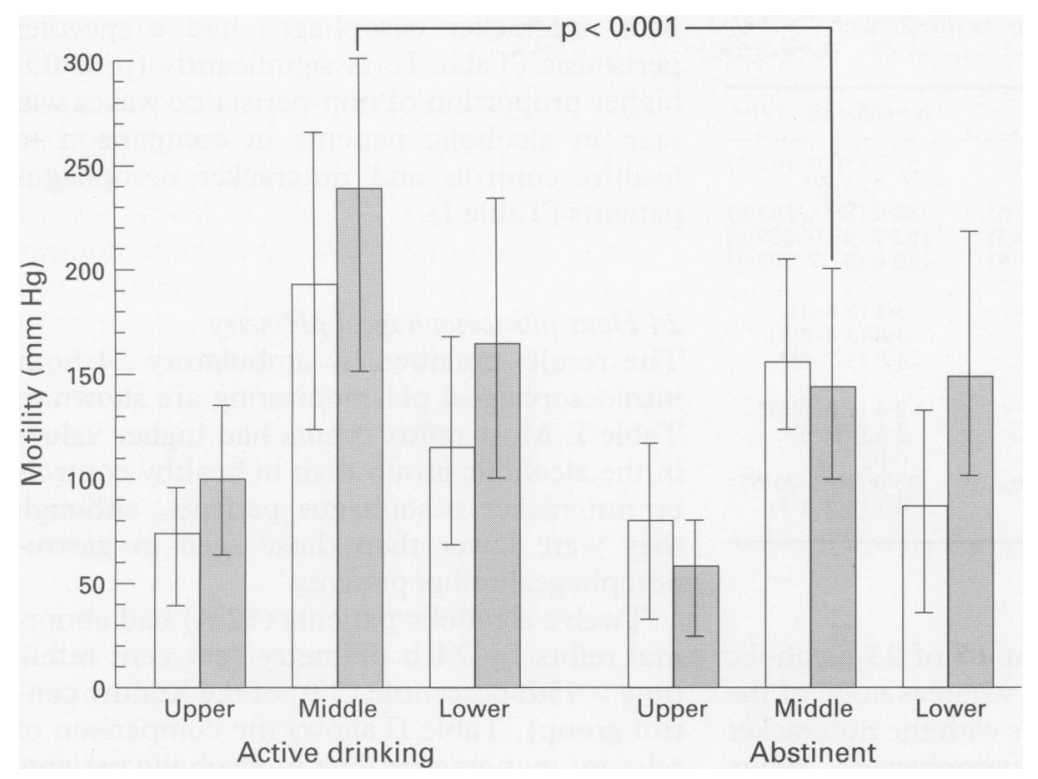

Figure 2: Median amplitude of peristaltic waves throughout the oesophagus at baseline (open columns) and six month (shaded columns) evaluation in six alcoholic patients who kept drinking and 13 alcoholic patients who remained abstinent. Bars represent interquartile ranges.

\section{Discussion}

In this investigation 23 chronic alcoholic patients were submitted to prospective evaluation of oesophageal function by means of endoscopy, oesophageal manometry, and ambulatory 24 hour intraoesophageal $\mathrm{pH}$ monitoring, which were performed 7-10 days after ethanol withdrawal and six months later. To minimise confounding factors only patients without systemic complications of alcoholism were studied. The baseline oesophageal motility and pH tracings of alcoholic patients were compared with those of matched groups of healthy controls, gastro-oesophageal reflux disease patients, and nutcracker oesophagus patients. Most alcoholic patients disclosed oesophageal dysmotility characterised by lower oesophageal sphincter hypertension, high amplitude contractions in the middle third of the oesophagus or a high frequency of nonperistaltic waves, or all three. In addition, alcoholic patients had a high prevalence of reflux. Oesophageal dysmotility improved after prolonged abstinence from alcohol.

A high frequency of reflux symptoms, oesophageal inflammation, and abnormal reflux by 24 hour pH monitoring was seen in our unselected population of heavy drinkers when studied shortly after alcohol withdrawal. Ambulatory $\mathrm{pH}$ monitoring was performed in the hospital setting to ensure compliance with alcohol and tobacco restriction, a difficult task in this population. On the basis of clinical experience, experimental studies in animals, ${ }^{17-19}$ and the observed short-term pHmetric effects of intoxicating doses of alcohol in healthy volunteers, ${ }^{2021}$ alcohol is widely acknowledged to be an important factor in the aetiology of gastro-oesophageal reflux disease. However, there are no prospective studies on the prevalence of gastro-oesophageal reflux disease in chronic alcoholic patients. In an oesophageal motility study with 18 alcoholic patients submitted to upper gastrointestinal endoscopy and biopsy, Keshavarzian et $a l^{6}$ found none with oesophageal symptoms and only one with microscopic oesophagitis. No reasonable explanation can be found for these discrepant results; the only difference between Keshavarzian patients' and ours is that the first group were mostly Afro-American. At any rate, our study has the advantage that reflux

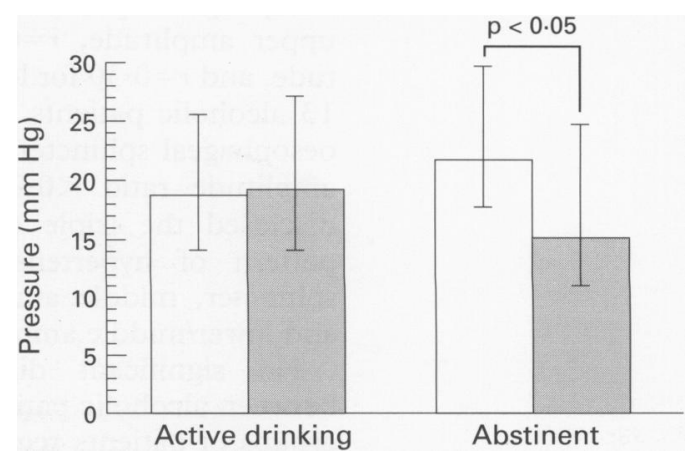

Figure 4: Median lower sphincter pressure at baseline (open columns) and six month (shaded columns) evaluation in six patients with continuous alcohol intake and 13 alcoholic patients who remained abstinent. Bars represent interquartile ranges.
Figure 3: Individual changes in the ratio between lower amplitude and middle amplitude of oesophageal peristalsis (medians) in six alcoholic patients who kept drinking and 13 alcoholic patients who remained abstinent. 
was confirmed by 24 hour oesophageal $\mathrm{pH}$ testing.

Numerous epidemiological studies have linked heavy drinking with the development of oesophageal neoplasms. ${ }^{22}$ In our series of 23 alcoholic patients, a single patient was discovered to have an asymptomatic (albeit invasive) oesophageal squamous carcinoma. A prospective study assessing the prevalence of reflux and oesophageal mucosal lesions in chronic alcoholic patients seems desirable.

Short-term administration of intoxicating doses of alcohol by either the oral or intravenous route to healthy volunteers has been reported to induce both a decrease ${ }^{12}$ and no changes ${ }^{3}$ in lower oesophageal sphincter pressure. In contrast, lower oesophageal sphincter pressure has been found to be increased in chronic alcoholic patients studied after different withdrawal periods. ${ }^{156}$ Our results agree with the latter findings. Lower oesophageal sphincter pressure was increased in comparison to both healthy controls and gastrooesophageal reflux patients, but the values were similar to those of the nutcracker oesophagus group. Thirteen of 23 patients (57\%) had a lower oesophageal sphincter pressure above the 95th percentile of the healthy control group and could thus be considered hypertensive lower oesophageal sphincter. This is a manometric diagnosis in some patients referred for study of dysphagia or non-cardiac chest pain, or both. ${ }^{23-25}$ It seems that alcoholism should also be considered when oesophageal motility testing shows a hypertensive lower oesophageal sphincter. Surprisingly, despite overall high lower oesophageal sphincter pressures, a significant proportion of our patients had abnormal reflux. A possible explanation for these discordant findings could be that alcohol increases spontaneous relaxations of the lower oesophageal sphincter, ${ }^{26}$ but this aspect was not tested in our study.

Similar to its effects on lower oesophageal sphincter pressure, oral or intravenous administration of ethanol to healthy subjects causes a decrease of oesophageal contraction amplitude $^{13}$ whereas alcoholic patients studied during abstinence have hyperkinetic peristaltic waves. ${ }^{16}$ Previous manometric studies ${ }^{16}$ in chronic alcoholic patients have reported a close to $50 \%$ frequency of nutcracker oesophagus. The criteria for this oesophageal motility disorder have been defined as middle oesophageal third amplitude $>150 \mathrm{~mm} \mathrm{Hg}$ or distal amplitude $>180 \mathrm{~mm} \mathrm{Hg}{ }^{27}$ Using the first criterion, this diagnosis could be established in 13 of our 23 patients. Curiously, however, 15 patients (11 with middle oesophageal amplitude $>150$ $\mathrm{mm} \mathrm{Hg}$ ) had a ratio of lower/middle amplitude $<0.9$, a finding not present in the control groups (Fig 1) and, to our knowledge, not previously reported. The fact that at least three quarters of peristaltic waves of the overall study group showed this abnormality supports its relation to alcoholism. The decreased strength of distal oesophageal contractions was independent of abnormal reflux as assessed by 24 hour pHmetry (Table II). Segmental high amplitude peristaltic contractions have been reported in patients with non-cardiac chest pain and considered as a variant of the nutcracker oesophagus ${ }^{28}{ }^{29}$; no details about alcohol consumption are provided in these reports.

We also found significant differences in the number of tertiary or non-peristaltic contractions in alcoholic patients compared with healthy controls or nutcracker oesophagus patients. An increased number of tertiary waves in subjects with clinically manifest peripheral neuropathy has been reported. ${ }^{4} \mathrm{We}$ studied patients without overt neurological damage; 10 of 23 patients had subclinical neuropathy by specific testing, but its presence did not influence oesophageal function. Other authors $^{6}$ have found that the existence of peripheral neuropathy was not a prerequisite for the detection of non-peristaltic contractions.

When studying alcoholic patients again after six months of abstinence, a reversal towards normal of the principal motility abnormalities was seen: lower oesophageal sphincter pressure decreased and changed lower/middle amplitude ratios tended to return to normal. In contrast, such abnormalities persisted in a small group of alcoholic patients who kept drinking. These findings support the notion that the oesophageal motility abnormalities described are related to alcoholism.

As none of the patients exhibited alcohol withdrawal symptoms as assessed by the CIWA scale, and patients with high blood alcohol concentrations at late evaluation also showed oesophageal motility abnormalities, these cannot be explained by the withdrawal syndrome. On the other hand, in our study oesophageal hypercontractility was not related either to autonomic neuropathy or to gastrooesophageal reflux. These abnormalities of oesophageal motor function may be attributed to the acute or subacute effects of ethanol on smooth muscle cells. In fact, experimental studies have shown that high concentrations of ethanol cause spasm of the muscle fibres of isolated blood vessels. ${ }^{30} 31$ Because ethanol decreases cytosolic free calcium ions, alcohol induced muscle hypercontractility must depend on the release of yet unknown neurotransmitters. ${ }^{32} \mathrm{~A}$ reasonable explanation is lacking, however, for the finding that contractions in the middle oesophagus are much stronger than in the rest of the oesophageal body in our alcoholic patients. Perhaps there are regional differences in the response of oesophageal smooth muscle cells to ethanol; experimental studies with isolated segments of the oesophagus could help solve this issue.

In summary, the results of this study suggest the existence of a specific oesophageal motility pattern in chronic alcoholism: high amplitude contractions of the middle third of the body of the oesophagus with inversion of the ratio lower/middle amplitude associated with a hypertensive lower oesophageal sphincter. Alcohol related oesophageal dysmotility seems to be reversible after abstinence.

This study was supported in part by grants $90 / 505$, and $91 / 344$ from FISSS, Spanish Ministry of Health. 


\section{Addendum}

To ascertain whether the oesophageal dysmotility pattern that we saw in this study of unselected alcoholic patients was useful as a marker of longterm alcoholism, we prospectively sought its occurrence in patients referred to our Digestive Motility Unit from August 1993 to July 1994. Of 358 patients submitted to oesophageal motility studies during this period, 26 gave a history of heavy drinking. There were 21 men, five women (mean age 42, range 23-61 years). We found the following manometric values (median and ranges): lower oesophageal sphincter pressure $24.6 \mathrm{~mm} \mathrm{Hg}(16 \cdot 2-53.2)$; upper amplitude $76.9 \mathrm{~mm} \mathrm{Hg}(34 \cdot 6-214 \cdot 6)$; middle amplitude $165 \cdot 1 \mathrm{~mm} \mathrm{Hg}(68 \cdot 5-331 \cdot 3)$; lower amplitude $109 \cdot 8 \mathrm{~mm} \mathrm{Hg}(53 \cdot 1-249 \cdot 6)$; upper oesophageal sphincter pressure $52.6 \mathrm{~mm} \mathrm{Hg}(31 \cdot 6-108 \cdot 0)$; non-peristaltic waves $0 \%(0-100)$. Nineteen of $26(73 \%)$ patients had a middle amplitude $>150 \mathrm{~mm} \mathrm{Hg}$, and $20(77 \%)$ had a lower/middle amplitude ratio $<0.9$. Four patients $(15 \%)$ disclosed the triple oesophageal dysmotility pattern of hypertensive lower oesophageal sphincter, middle amplitude $>150 \mathrm{~mm} \mathrm{Hg}$, and lower/middle amplitude $<0 \cdot 9$. These findings strongly support the notion that high amplitude contractions in the middle third of the oesophagus is related to heavy drinking and can be considered as a manometric marker of alcoholism.

1 Keshavarzian A, Polepalle C, Iber FL, Durkin M. Esophageal motor disorders in alcoholics: result of alcoholism or withdrawal? Alcohol Clin Exp Res 1990; 14: 561-7

2 Hogan WJ, Viegas DE, Andrade SR, Winship DH. Ethanol induced acute esophageal motor dysfunction. $\mathcal{f} A p p l$ Physiol 1972; 32: 755-60.

3 Mayer EM, Grabowski CJ, Fisher RS. Effect of graded doses of alcohol upon esophageal motor function. Gastroenterology 1978; 76: 1133-6.

4 Winship DH, Caflisch CR, Zboralske FF, Hogan WJ. Deterioration of esophageal peristalsis in patients with Deterioration of esophageal peristalsis in patients with

Silver LS, Worner TM, Korsten MA. Esophageal function in chronic alcoholics. Am $\mathcal{F}$ Gastroenterol 1986; 81: 423-7. 6 Keshavarzian A, Iber FL, Ferguson Y. Esophageal manometry and radionuclide emptying in chronic alcoholics. Gastroenterology 1987; 92: 651-7.

7 Keshavarzian A, Polepalle C, Iber FL, Durkin M. Secondary esophageal contractions are abnormal in chronic alcoholics. Dig Dis Sci 1992; 37: 517-22.

8 Burbige EJ, Lewis DR, Halsted CH. Alcohol and the gastrointestinal tract. Med Clin North Am 1984; 68: 77-89.

9 Wienbeck M, Berges W. Esophageal lesions in the alcoholic. Clin Gastroenterol 1975; 10: 375-8.
10 American Psychiatric Association. Diagnostic and statistical manual of mental disorders. 3rd ed. Washington, DC: American Psychiatric Press, 1987.

11 Monforte R, Estruch R, Valls-Solé J, Nicolás JM, Villalta J, Urbano-Marquez A. Autonomic and peripheral neuropathies in chronic alcoholism: a dose related toxic effect of pathies in chronic alcoholism: a dose re

12 Naranjo CA, Sellers EM. Clinical assessment and pharmacology of alcohol withdrawal syndrome. In: Galanter $\mathbf{M}$, ed. Recent developments in alcoholism. New York: Plenum Publishing, 1986: 265-81.

13 Ros E, Toledo-Pimentel V, Bordas JM, Grande L, Lacima $G$, Segú $L$. Healing of erosive esophagitis with sucralfate and cimetidine. Influence of pretreatment lower esophageal sphincter pressure and serum pepsinogen I levels. Am f Med 1991; 91 (suppl 2A): 107-12S.

14 Grande L, Lacima G, Ros E, Pujol A, García-Valdecasas JC, Fuster J, et al. Dysphagia and esophageal motor dysfunction in gastroœsophageal reflux are corrected by fundoplication. $\mathcal{F}$ Clin Gastroenterol 1991; 13: 11-6.

15 Grande L, Culell P, Ros E, Pujol A, Garcia-Valdecasas JC, Fuster J, et al. Comparison of stationary vs ambulatory 24hour $\mathrm{pH}$ monitoring systems in the diagnosis of gastroesophageal reflux disease. Dig Dis Sci 1993; 38: 213-9.

16 DeMeester TR, Johnson LF, Joseph GJ, Toscano MS, Hall AW, Skinner DN. Patterns of gastroesophageal reflux in health and disease. Ann Surg 1976; 184: 459-70.

17 Chung RSK, Johnson GM, DenBesten L. Effects of sodium taurocholate and ethanol on hydrogen ion absorption in rabbit oesophagus. Dig Dis Sci 1977; 22: 582-8.

18 Shirazi SS, Platz CE. Effects of alcohol on canine esophageal mucosa. 7 Surg Res 1978; 25: 373-9.

19 Salo JA. Ethanol-induced mucosal injury in rabbit esophagus. Scand $f$ Gastroenterol 1983; 18: 713-21.

$20 \mathrm{~K}$ jellin $\mathrm{G}$, Tibbling $\mathrm{L}$. Influence of body position, dry and water swallows, smoking, and alcohol on esophageal acid clearing. Scand $\mathcal{f}$ Gastroenterol 1978; 13: 282-8.

21 Kaufman SE, Kaye MD. Induction of gastro-esophageal reflux by alcohol. Gut 1978; 19: 336-8

22 Yakshe PN, Fleischer DE. Neoplasms of the esophagus. In: Castell DO, ed. The esophagus. Boston: Little, Brown, 1992: 277-98.

23 Code CF, Schlegel JF, Kelley ML, Olsen AM, Ellis JH. Hypertensive gastroesophageal sphincter. Proc Mayo Clin 1960; 35: 391-9.

24 Freidin N, Traube M, Mittal RK, McCallum RW. The hypertensive lower esophageal sphincter. Manometric and hypertensive lower esophageal sphincter. Manom

25 Waterman DC, Dalton CB, Ott DJ, Castell JA, Bradley LA, Castell DO, et al. Hypertensive lower esophageal sphincter: What does it mean? $\mathcal{f}$ Clin Gastroenterol 1989; 11: 139-46.

26 Dent J, Holloway RH, Tooli J, Dodds WJ. Mechanisms of lower oesophageal sphincter incompetence in patients with symptomatic gastro-oesophageal reflux. Gut 1988; 29: $1020-8$.

27 Dalton CB, Castell DO, Richter JE. The changing faces of the nutcracker esophagus. Am 7 Gastroenterol 1988; 83: 623-8.

28 Freidin N, Mittal RK, Traube M, McCallum RW. Segmental high amplitude peristaltic contractions in the

29 Achem SR, Kolts BE, Burton L. Segmental versus diffuse nutcracker esophagus: an intermittent motility pattern. Am $\mathcal{F}$ Gastroenterol 1993; 88: 847-51.

30 Altura BM, Altura BT, Gebrewold A. Alcohol-induced spasms of cerebral blood vessels: relation to cerebrovascular accidents and sudden death. Science 1983; 220: 331-3.

31 Altura BM, Altura BT. Peripheral and cerebrovascular actions of ethanol, acetaldehyde, and acetate: relationship to divalent cations. Alcohol Clin Exp Res 1987; 11: 99-111.

32 Zhang A, Chen TPO, Altura BM. Ethanol decreases cytosolic-free calcium ions in vascular smooth muscle cytosolic-free calcium ions in vascular smooth muscle Res 1992; 16: 55-7. 